\title{
Optimization of modes for processing water-ice cleaning of machine parts
}

\author{
Mikhail Burnashov ${ }^{1, *}$, and Alexander Prezhbilov ${ }^{1}$ \\ ${ }^{1}$ Orel State University of I.S. Turgenev, Orel, Russian Federation
}

\begin{abstract}
At present, the development of technologies for cleaning various surfaces from coatings, contaminants and deposits is very relevant. It becomes even more important when the coating material has to be prepared for a secondary use, and in respect of the surface being cleaned its physical and mechanical properties and shape are not allowed to change.
\end{abstract}

\section{Introduction}

Among the known cleaning techniques, the most universal and promising are the jet methods [1-3]. At the same time, the most productive is the technology based on the use of hydroabrasive jets [1]. However, along with the high performance, there is a number of shortcomings that limit the scope of its application. It has to be taken in consideration the cost of the abrasive material, its irreversible consumption issues and its utilization. At the same time mixing the abrasive with the coating material makes the reuse of the latter very difficult.

\section{Problem description}

Therefore, it is important to consider the possibility of increasing the efficiency of abrasive jetting by finding a replacement for sand which is the traditional abrasive material. Being a solid material, ice has a great destructive force when struck, and also meets environmental and economic requirements. The efficiency of cutting nonmetallic sheet materials with a high-pressure water-ice jet was confirmed in the works $[2,3]$. However, the formation of the cutting water-ice jet was different than in the proposed method for cleaning. A highpressure water jet of 0.15-0.3 mm in diameter was mixed with a liquid nitrogen flow on the principle of ejection, resulting in the formation of a three-phase structure - a water-ice jet and gaseous nitrogen. Such a "cutting tool" was applied to the nonmetallic sheet material to be cut.

The main technical solution with the use of ice that allows creating the required cleaning performance comparable to the abrasive jetting performance is the use of readily available solid ice particles of 1.5-2 mm size. These particles introduced to the high-speed water jet and are widely used for abrasive waterjet cutting [4].

\footnotetext{
* Corresponding author: stker@,rambler.ru
} 
However, in addition to solving the technical problems of the water-ice jet formation, it is important to determine the purification stages in which the process will have the greatest efficiency.

\section{Experiment}

Studies aimed at optimizing the modes of the machine parts water-ice jet cleaning were carried out on a special bench consisting of the following main units: high-pressure pump of multiplier type 1, waterjet tool 2, sliding table with brackets for holding the samples 3 (fig. 1). Pump 1 allows providing water pressure up to $100 \mathrm{MPa}$ and regulates its flow rate to $30 \mathrm{l} / \mathrm{min}$. Test specimens with different physical and mechanical properties were attached to the sliding table 3 by means of special brackets. Sliding table was driven by an electric motor with a thyristor converter and a screw drive. The supply of prepared ice particles was delivered to the waterjet tool via flexible tubing 4 . To record the pressure, the first-class precision indicating pressure gauges installed at the outlet of the pumping unit were used.

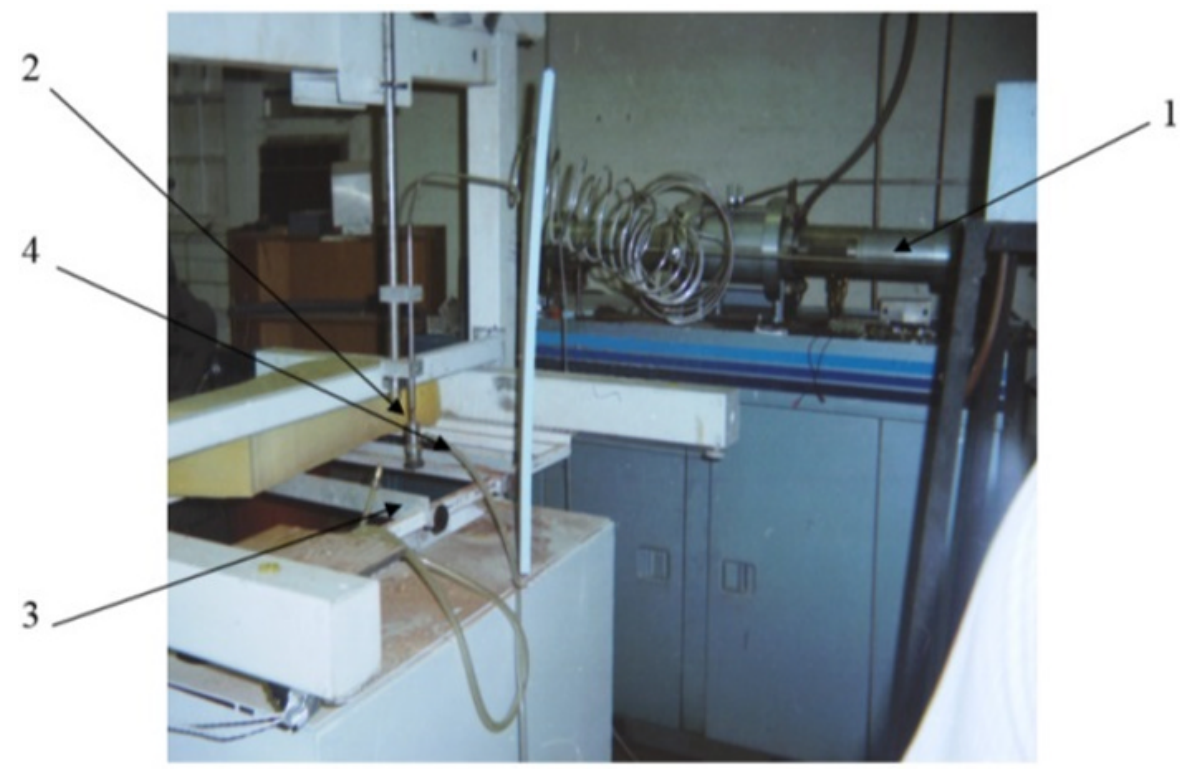

Fig. 1. Test bench.

Asphalt-resinous deposits were used as the material to be removed. The composition and properties of asphalt-resinous and paraffin deposits (ARPD) is not a simple mixture of asphaltenes, resins and paraffins, but rather a complex structured system with a pronounced core of asphaltenes and a sorption-solvate layer of petroleum resins (CCE). Asphaltresinous materials (ARM) are heterocyclic compounds of a complex hybrid structure, which include nitrogen, sulfur, oxygen and metals (Fe, $\mathrm{Mg}, \mathrm{V}, \mathrm{Ni}, \mathrm{Ca}, \mathrm{Ti}, \mathrm{Mo}, \mathrm{Cu}, \mathrm{Cr}$, etc.). Up to $98 \%$ of ARM are aromatic and naphthenic structures [5]. The molecular structure of resins and asphaltenes forms a hydrocarbon skeleton accounting for $70-90 \%$ of the molecules total weight. There is a gradual trend of hydrogen depletion and carbon enrichment in the genetically related hydrocarbon-resins-asphaltenes series. The concentration of aromatic elements of the structure increase is directly proportional to the increase of the degree of their condensation. The share of carbon atoms in the periphery is inversely proportional to the specific weight of atoms in the central nucleus of molecules 
(i.e. the polynuclear structure with a strong predominance of aromatic rings). Resins and asphaltenes also differ in the content of nitrogen and oxygen. Oxygen is mainly concentrated in resins and nitrogen in asphaltenes. Depending on the nature of the oil and the content of solid hydrocarbons in it, as well as on the place of sampling, the composition of the deposits includes [6]: paraffins $-9 \ldots 77 \%$; resins $-5 \ldots 30 \%$; asphaltenes $-0.5 \ldots$ $70 \%$; associated oil up to $60 \%$; mechanical impurities - $1 \ldots 10 \%$; water - from fractions to several percent; sulfur - up to $2 \%$.

In the course of the experiments jet-forming nozzles were used with a diameter $\mathrm{d}_{0}=$ $0.003-0.006 \mathrm{~m}$ and a discharge coefficient $\mu=0.6$; water pressure $\mathrm{P}_{0}=30 \mathrm{MPa}$. The distance from the instrument to the surface to be cleaned $1_{0}$ varied from 0.05 to $0.07 \mathrm{~m}$. The results of the experiments are presented in the table 1 and in Fig. 2.

Table 1. Influence of regime parameters on energy capacity of water-ice cleaning

\begin{tabular}{|c|c|c|c|c|c|c|}
\hline $\mathrm{d}_{0}$ & 10 & b & $\mathrm{h}$ & $\mathrm{E}_{0}$ & $E_{0}=f\left(1_{0}\right)$ & $\mathrm{E}_{0}=0$ \\
\hline 1 & 2 & 3 & 4 & 5 & 6 & 7 \\
\hline 0,0003 & 0,05 & 0,008477 & 0,0033 & 1,11092 & \multirow{5}{*}{$\begin{array}{l}\mathrm{E}_{0}=46,7781_{0}{ }^{2} \\
-5,69811_{0}+ \\
1,2789\end{array}$} & \multirow[t]{5}{*}{0,061} \\
\hline 0,0003 & 0,055 & 0,008773 & 0,0032 & 1,106983 & & \\
\hline 0,0003 & 0,06 & 0,009069 & 0,0031 & 1,105396 & & \\
\hline 0,0003 & 0,065 & 0,009365 & 0,003 & 1,10614 & & \\
\hline 0,0003 & 0,07 & 0,009661 & 0,0029 & 1,109223 & & \\
\hline 0,0004 & 0,05 & 0,008896 & 0,0038 & 1,634324 & \multirow{5}{*}{$\begin{array}{l}\mathrm{E}_{0}=367,021_{0}{ }^{2} \\
-40,1761_{0}+ \\
2,7255\end{array}$} & \multirow[t]{5}{*}{0,054} \\
\hline 0,0004 & 0,055 & 0,009192 & 0,0037 & 1,624444 & & \\
\hline 0,0004 & 0,06 & 0,009488 & 0,00355 & 1,640263 & & \\
\hline 0,0004 & 0,065 & 0,009784 & 0,0034 & 1,660815 & & \\
\hline 0,0004 & 0,07 & 0,01008 & 0,0032 & 1,712798 & & \\
\hline 0,0005 & 0,05 & 0,009315 & 0,0051 & 1,81712 & \multirow{5}{*}{$\begin{array}{l}\mathrm{E}_{0}=1566,91_{0}{ }^{2} \\
-160,3610+ \\
5,9056\end{array}$} & \multirow[t]{5}{*}{0,051} \\
\hline 0,0005 & 0,055 & 0,009611 & 0,005 & 1,796379 & & \\
\hline 0,0005 & 0,06 & 0,009907 & 0,0045 & 1,936341 & & \\
\hline 0,0005 & 0,065 & 0,010203 & 0,004 & 2,115187 & & \\
\hline 0,0005 & 0,07 & 0,010499 & 0,0035 & 2,349203 & & \\
\hline 0,0006 & 0,05 & 0,009734 & 0,0065 & 1,964692 & \multirow{5}{*}{$\begin{array}{l}\mathrm{E}_{0}=573,261_{0}^{2} \\
-\quad 56,5861_{0}+ \\
3,3539\end{array}$} & \multirow[t]{5}{*}{0,049} \\
\hline 0,0006 & 0,055 & 0,01003 & 0,0063 & 1,967241 & & \\
\hline 0,0006 & 0,06 & 0,010326 & 0,006 & 2,006392 & & \\
\hline 0,0006 & 0,065 & 0,010622 & 0,0055 & 2,127797 & & \\
\hline 0,0006 & 0,07 & 0,010918 & 0,0052 & 2,189539 & & \\
\hline
\end{tabular}



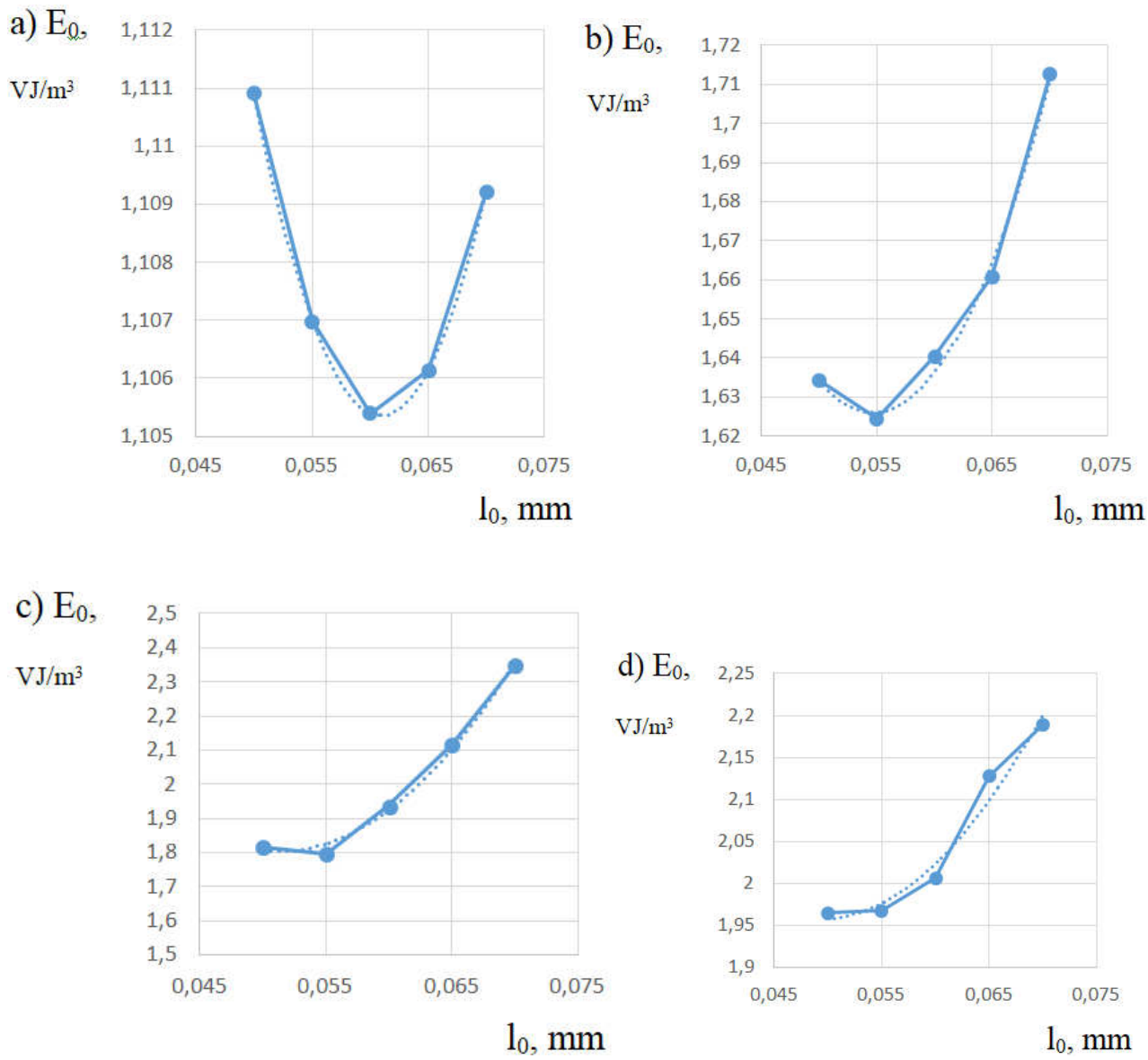

Fig. 2. Dependences of energy consumption of water-ice cleaning from the distance from the tool to the surface being cleaned:a) - d0 $=0,003 \mathrm{~m} ; \mathrm{b})-\mathrm{d} 0=0,004 \mathrm{~m} ; \mathrm{c})-\mathrm{d} 0=0,005 \mathrm{~m} ; \mathrm{d})-\mathrm{d} 0=0,006 \mathrm{~m}$.

\section{Conclusion}

Analysis of the data presented shows that as the distance from the tool increases to the surface to be cleaned 10 , the width of the material to be removed b increases, while its depth $\mathrm{h}$ decreases. The volume of material to be removed $\mathrm{V}$ per unit time:

$$
V=b \times h \times v
$$

where: $\mathrm{v}$ - velocity of the jet movement $(\mathrm{v}=1 \mathrm{~m} / \mathrm{sec})$.

The ratio of the consumed hydraulic power to the volume of the material removed characterizes the energy consumption of the process E0, which first decreases with increasing distance from the tool to the surface to be cleaned, and then goes back up. In this case, the conformity has a region of pronounced extremum, and the extremum point corresponds to the purification stage with the lowest energy intensity.

The experimental data processing made it possible to obtain a formula for calculating the rational distance from the tool to the surface to be cleaned, depending on the diameter of the jet-forming nozzle, which ensures the minimum energy intensity of the water-ice jet cleaning process for the tool of the adopted design. 


$$
l_{\text {oopt }}=0,0097 d_{0}-0,315
$$

The resulting formula can be used to calculate the cleaning stages for a particular surface. At the same time, it is obvious that in order to make the dependence universal, it is necessary to study the effect on the efficiency of the strength properties of the material being removed.

\section{References}

1. Yu.S. Kozlov, O.K. Kusnetsov, A.F. Tel'nov. Cleaning products in engineering. (Mashinostroenie, Moscow, 1982)

2. Yu.S. Stepanov, M.A. Burnashov, K.A. Golovin. Progressive technologies of hydrojet cutting of materials. (TulGU, Tula, 2009)

3. M.A. Burnashov. Increasing the efficiency of cutting sheet nonmetallic materials with high-pressure water jets. Thesis abstract for the degree of doctor of technical Sciences. Oryol State Technical University, Orel, 37 p. (2010)

4. M.A. Burnashov, A.N. Prezhbilov and E.Yu. Stepanova. Modelling of destructive ability of water-ice-jet while machine processing of machine elements. MATEC Web Conf. V. 129, no 1-4. (2017)

5. A.V. SHarifullin, L.R. Bajbekova, A.T. Sulejmanov. Features of composition and structure of oil deposits. Tekhnologii nefti i gaza, Moscow, vol 6, pp. 19-24 (2006)

6. S.R. Sergienko, B.A. Taimova, E.I. Tatalaev. High molecular weight non-hydrocarbon oil compounds. (Nauka, Moscow, 1959)

7. M.A. Burnashov, A.N. Prezhbilov. Study of energy parameters of machine parts of water-ice jet cleaning applications. The XI International Conference on Mechanical Engineering, Automation and Control Systems (MEACS 2017). Tomsk Polytechnic University, Tomsk, v. 327. (2018)

8. B-L Liu, L-H Liu. Papers presented at the 14th Internationals on Jetting Technology. Held in Brugge, Belgium, 21-23 September, pp. 203-210

9. H. Kiyohashi, K. Handa. Proceedings of the International Symposium on New Applications of Waterjet Technology, Ishinomaki, Japan, pp. 51-60 (1999)

10. H. Liu, T. Butler. Processing of the new applications of water jet technology. Isinomaki, Japan, pp. 51 - 60 (1999)

11. Water jet cutting: a production tool. Machining and Production Engeneering., vol. 141, no 3631. pp. 18-19 (1983)

12. M.A. Burnashov, A.N. Prezhbilov. Cleaning of surfaces of details of cars with the water ice stream with in advance prepared particles. Transport and Technological Cars. Orel State University of I.S. Turgenev, Orel, v. 3, pp. 46-50 (2015)

13. A.Y. Pushkarev, K.A. Golovin, A.B. Zabin, Y.I. Yeruhimivich, Proceeding of the International Symposium on New Applications of Water Jet Technology. Oktober 1921, Ishinomaki, Japan. Ishinomaki Senshu Universiti, pp. $421-425$ (1999)

14. T.J. Louis, 5th American Waterjet Conference, Toronto, Canada, August, pp. 145 168 (1989)

15. M. Hessling, 9th International Symposium on Jet Cutting Technology, Sendai, Japan, October, paper G3, pp. 357 - 376 (1988)

16. P. Etchells. Aerosp. Compos, and Mater, vol 3, no 1, pp. 40 - 43 (1991)

17. Anon, High Pressure Water Jet Systems, Part 2, no. 4, pp. 20 -23 (1993) 
18. Yazici, Sina Abrasive Jet Cutting and Drilling Rock, Ph.D. Dissertation in Mining Engineering, University of Missouri - Rolla, Rolla, Missouri, 203 p. (1989)

19. K. Faber, H. Oweinah, 10th International Symposium on Jet Cutting Technology, Amsterdam, v. 25, pp. 365 - 384 (1990)

20. E.J. Chalmers, 6th American Water Jet Conference, Houston, Texas, pp. 345 - 354 (1991 